Dr BOŠKO MIJATOVIĆ, viši naučni saradnik

Centar za liberalno-demokratske studije

Beograd, Kralja Milana 7

UDK 336.743(497.1)"1919/1921"

336.748.5(497.1)"1918/1921"

\title{
ZAMENA AUSTRIJSKIH KRUNA ZA DINARE 1920. GODINE (drugi deo) ${ }^{1}$
}

\begin{abstract}
APSTRAKT: $U$ drugom delu članka razmatra se kritika zamene austrijskih kruna dinarima od strane više autora. Njihova osnovna tvrdnja jeste da je kurs razmene kruna-dinar od 4:1 bio nepravedan, čak pljačkaški, zbog njihove navodne jednakosti kupovnih snaga. Problem je samo to što ova tvrdnja nikada nije potkrepljena empirijskim materijalom. U tekstu iznosimo ondašnje cene više artikala, uglavnom poljoprivrednih, koje pokazuju da je kupovna snaga dinara u trenutku zamene bila znatno veća (verovatno 3-4 puta) nego krune. Druga primedba da je vlada namerno propustila da izvrši zamenu odmah po ujedinjenju - svakako ne stoji iz tehničkih i političkih razloga. Neki od ondašnjih kritičara čak su izneli katastrofička predviđanja o ekonomskom kolapsu zemlje zbog izvedene zamene, koja se nisu ostvarila.
\end{abstract}

Ključne reči: kruna, dinar, zamena novca, kurs, Jugoslavija

\section{Diskusija o unifikaciji}

Pogledi na zamenu kruna 1920. i danas su veoma različiti na južnoslovenskom prostoru. U hrvatskoj ozbiljnijoj literaturi uverljivo dominira tvrdnja da je u pitanju nepravedna i štetna operacija na račun hrvatskih i prečanskih krajeva od strane srpske vlade. Hrvoje Matković u uticajnoj Povijesti Jugoslavije samo kratko kaže da su kroz zamenu „u korist Srbije teško bili oštećeni svi dijelovi nove države koji su ranije bili pod austrougarskom vlašću“. ${ }^{2}$ I Ivo Banac tvrdi da je odnos 4:1 bio „potpuno neopravdan“ i da je štednja stanovništva bitno smanjena, ${ }^{3}$ a Franjo Tuđman navodi da su

${ }^{1}$ Zahvaljujem se Borisu Begoviću, Ljubomiru Madžaru i Branku Milanoviću na korisnim sugestijama. Odgovornost za preostale slabosti isključivo je moja.

${ }^{2}$ H. Matković, Povijest Jugoslavije (1918-1991), Hrvatski pogled, Zagreb 1998, 147.

${ }^{3}$ I. Banac, n. d., 223 i 224. 
prečanske zemlje zamenom „grubo osiromašene“. ${ }^{4}$ I autori koji su kritični prema "domoljubnoj" istoriografiji govore isto: Ivo Goldštajn da je "tadašnja stvarna vrijednost dviju valuta bila podjednaka“, ${ }^{5}$ a Alojz Ivanišević da je „prema tadašnjoj stvarnoj vrijednosti dviju valuta taj odnos trebao biti $1: 1 "{ }^{6}$ Najzanimljivije je to što pomenuti autori ne navode ni argumente ni reference kojima bi potkrepili svoje tvrdnje, kao da se radi o opšteprihvaćenoj naučnoj istini, što svakako nije tačno.

U manje ozbiljnoj hrvatskoj literaturi i publicistici, kao i na blogsferi uzima se za dokazano da se radi o običnoj pljački. Takvo uverenje održava se još iz 1920, ali je popularisano knjigom Rudolfa Bićanića Ekonomska podloga hrvatskog pitanja, objavljenoj 1938. od strane Hrvatske seljačke stranke. Njen uticaj vidljiv je i u radovima novosadskog istoričara Borisa Krševa, koji tvrdi da je zamena krune bila „prva velika pljačka prečanskih krajeva". ${ }^{7}$ Slično govore i pamfleti Šime Đodana ${ }^{8}$ i Hakije Đozića. ${ }^{9}$

Potpuno drugačija slika može se naći u knjizi grupe autora Istina $o$ Ekonomskoj podlozi hrvatskog pitanja, odgovor g. dr Bićaniću, objavljenoj 1940, zatim kod Ivana Slokara ${ }^{10}$ i Jožeta Šorna (u pomenutim radovima), kao i kod Momčila Zečevića, ${ }^{11}$ Ivana Becića ${ }^{12}$ i Slobodana Vukovića. ${ }^{13}$ Stoga je potrebno ne samo ispitati ovu epizodu, već pogledati šta kritičari kažu i na kritiku eventualno baciti novo svetlo.

\section{Kupovna snaga krune i dinara}

Osnovna linija rezonovanja prečanskih kritičara vladinog načina unifikacije iz starije generacije je sledeća:

- kupovna snaga krune i dinara bila je podjednaka,

- kurs zamene treba da je određen odnosom kupovnih snaga krune i dinara,

${ }^{4}$ F. Tuđman, Hrvatska u monarhističkoj Jugoslaviji, knj. I, 1918-1928, Zagreb 1993, 298.

${ }^{5}$ I. Goldstein, Hrvatska 1918-2008, Zagreb 2008, 31.

${ }^{6}$ A. Ivanišević, „Kao guske u maglu? Položaj Hrvatske u prvoj jugoslavenskoj državi. Između mita i stvarnosti“, Radovi-Zavod za hrvatsku povijest, Vol. 42, 2010, 343.

${ }^{7}$ B. Kršev, Pet valuta i pet poreskih sistema, Danas, 15. juli 2008.

8 Š. Đodan, Hrvatsko pitanje, Zagreb 1981.

${ }^{9}$ H. Đozić, Kako je Kraljevina SHS opljačkala nekadašnje imaoce kruna Austro-Ugarske, Znakovi vremena, br. 28/2005.

${ }^{10}$ I. Slokar, Valutne razmere, devizna politika in bankarstvo, u: Slovenci v desetletju 1918-1928, Ljubljana 1928.

${ }^{11}$ M. Zečević, Srbija i valutno pitanje 1918-1921, u M. Zečević, Prošlost i vreme, Iz istorije Jugoslavije, Beograd 2003.

${ }^{12}$ I. Becić, Valutno pitanje u Kraljevini SHS, Leskovački zbornik, br. 45, 2005.

${ }^{13}$ S. Vuković, Srpsko društvo i ekonomija (1918-1992), Novi Sad 2012. 

nih snaga $\mathrm{i}$

- zamena od četiri krune za jedan dinar ne odgovara odnosu kupov-

- stoga je zamena nepravedna, pa i pljačkaška.

Problem s tvrdnjom da je kupovna snaga krune i dinara podjednaka je to što uopšte nije dokazana, a ni dokazivana. Uzimala se zdravo za gotovo, na poverenje, bez imalo truda da se argumentuje. Tako je Savez novčanih zavoda tvrdio da se „za žigosanu krunu dobiva ono isto što i za današnji dinar“, ${ }^{14}$ a direktor Saveza Ivan Krajač, ${ }^{15}$ još preciznije, da „kruna do markiranja ima veću, a po markiranju u proseku podjednaku snagu kao dinar u Beogradu“. ${ }^{16}$ Ili Bićanić: „Što se tiče kupovne snage na tržištu robe, ona je bila otprilike jednaka za krunu i za dinar... Kupovna snaga u zemlji je bila jednaka. Ono što je stajalo u Beogradu i Srbiji 10 dinara plaćalo se u Zagrebu i Hrvatskoj 10 kruna“. ${ }^{17}$ I to je sve. Ni ovde ne postoji neki argument, neka referenca, neke cene ili drugi podaci koji bi potkrepili iskaz, što je očigledna metodološka manjkavost koja je dovoljna za odbacivanje ove tvrdnje, posebno stoga što dolazi od zainteresovanih strana. Da bi se smelo tvrditi da je kupovna moć jednaka, trebalo bi raspolagati metodološki korektno napravljenim upoređenjem nivoa cena na krunskom i dinarskom području. ${ }^{18}$ Ali, ništa slično se ne pominje u raspoloživoj literaturi.

Postoje i drugačije procene. Tako se u zagrebačkom Obzoru još početkom 1919. pojavilo mišljenje da je je odnos dinara i krune po kupovnoj snazi 1,5:1. ${ }^{19}$ I Slovenec, organ Korošecove Narodne stranke, pomenuo je 1920. da je kupovna snaga dinara u Srbiji „dvaput veća nego kupovna snaga krune u Sloveniji“. ${ }^{20} \mathrm{Na}$ kraju, Mijo Mirković, savremenik i cenjeni hrvatski ekonomski istoričar, napisao je da je početkom 1920. kupovna snaga dinara bila tri puta veća nego krune. ${ }^{21}$

Mi ni danas ne raspolažemo metodološki korektnim poređenjem ondašnjih kupovnih snaga krune i dinara, ali možemo da navedemo neke primere uglavnom nađene $u$ tadašnjim novinama, što znači da su nepristrasni i svima dostupni.

${ }^{14}$ Lj. Kosier, n. d., 246-251.

${ }^{15}$ Krajač je bio i političar, prvo u Hrvatskoj zajednici, a zatim u HSS-u ispred koje je bio i ministar trgovine i industrije u vladama Nikole Pašića i Nikole Uzunovića 19251927. godine.

${ }^{16} \mathrm{Lj}$. Kosier, n. d., 291.

${ }^{17}$ R. Bićanić, n. d., 42-43.

${ }^{18}$ Za savremene metodologije upoređenja kupovnih snaga novca videti International Comparison Program: http://siteresources.worldbank. org/ICPEXT/Resources/ICP_2011.html, 5. januar 2013.

${ }^{19}$ Obzor, 1. mart 1919.

${ }^{20}$ Slovenec, 11. septembar 1920.

${ }^{21}$ M. Mirković, Ekonomska historija Jugoslavije, Zagreb 1958, 340. 
Upoređenje nekih cena za $1 \mathrm{~kg}$

\begin{tabular}{|l|r|r|r|r|}
\hline & $\begin{array}{c}\text { Vojvodina } \\
\text { velikoprodaja } \\
\text { 17. 12.1919. } \\
\text { kruna }\end{array}$ & $\begin{array}{c}\text { Beograd } \\
\text { maloprodaja } \\
\text { 15. 12. 1919. } \\
\text { dinara }\end{array}$ & $\begin{array}{c}\text { Užički kraj } \\
\text { velikoprodaja } \\
\text { XII 1919. } \\
\text { dinara }\end{array}$ & Odnos \\
\hline Mast & 33,5 & 10 & & 3,3 \\
\hline Pasulj & 5,6 & 2,3 & & 2,5 \\
\hline Svinjsko & 19,7 & 7 & & 2,8 \\
\hline Goveđe & 17,4 & 7 & & 2,5 \\
\hline Belo brašno & 7,1 & 3 & & 2,4 \\
\hline Pšenica & $\mathbf{4 , 0}$ & & 1,3 & 3,0 \\
\hline
\end{tabular}

Napomene: Cene za Vojvodinu obračunate su kao neponderisani prosek za 11 gradova u Baranji, Bačkoj i Banatu, a za užički kraj kao neponderisani prosek za 4 grada; velikoprodajne cene su originalno izražene za $100 \mathrm{~kg}$.

Izvori: Užički kraj: A. Miletić, Unutrašnja trgovina u Kraljevini SHS 1919. godine, Tokovi istorije, br. 3-4, Beograd 2003, 12; Beograd i Vojvodina: Trgovinski glasnik, 16. i 23. decembar 1919.

Kako se jasno vidi, cene u krunama u Vojvodini znatno su više nego cene u dinarima u Srbiji, tako da tvrdnja o jednakoj kupovnoj snazi krune i dinara nije istinita. Prosečan odnos cena iz prethodne tabele je 2,7:1. On je realno bio i veći jer ove cene nisu jednake vrste: krunske su velikoprodajne, a beogradske maloprodajne. Pošto su svakako krunske $u$ maloprodaji bile više nego navedene velikoprodajne (za transportne troškove, preduzetničku dobit i oduzimanje popusta za kupovinu na veliko), to bi odnos porastao sa tih 2,7:1 na 3:1 ili 4:1.

Drugo, u januaru 1920. kilogram goveđeg mesa na pijaci u Beogradu koštao je prosečno 7 dinara, a u Ljubljani je propisana cena bila 15,70 kruna, dok je bilo mesara koji su ga prodavali po 18 kruna, što daje odnos od oko 2,5:1. Ili, maloprodajna cena brašna se tada u Beogradu kretala od 1,60 do 3,10 dinara, zavisno od vrste, a u Zagrebu su cene adminstrativno maksimirane na 9 do 12 kruna po kilogramu, što daje odnos od oko 4:1. ${ }^{22}$

Treće, cena i Jugoslavenskog (Hrvatskog) lojda i Trgovinskog glasnika, dveju sličnih privrednih novina, iznosila je u decembru 1919. jednu krunu, ali se ovaj drugi prodavao i za 20 para. Iste cene u krunama i dinarima kao Trgovinski glasnik imale su Pravda i Politika. Znači, cena zagrebačkog i beogradskih listova bila je jednaka u krunama, ali je dinarska u beogradskim

${ }^{22}$ Trgovinski glasnik, 19. februar 1920; Slovenski narod, 16. januar 1920; Slovenec, 8. januar 1920. 
bila znatno niža i davala kurs od 5:1. Slovenački listovi bili su jeftiniji: Slovenec, Slovenski narod i Nova doba 60 filera, ali je to još uvek odnos 3:1 prema cenama beogradskih listova u parama.

Ovi primeri jasno indiciraju netačnost tvrdnje o jednakosti kupovnih snaga, odnosno izvesnost da je kupovna moć dinara bila veća nego krune. Kako se slažu sa pomenutim ocenama Obzora, Sloveneca i, posebno, Mije Mirkovića, može se zaključiti da je najverovatnije u trenutku odluke kupovna snaga dinara bila daleko veća nego krune.

Ekonomski gledano, jednakost kupovnih snaga dveju valuta i njihov bitno različit berzanski kurs nikako ne idu zajedno, pa nije moguće da je kupovna snaga krune i dinara jednaka kada je njihov kurs krajem 1919. bio oko 4:1. Čak i da su, usled nekog vanrednog razloga, u jednom trenutku uspostavili i jednakost cena i kurs 4:1, odmah bi na delo stupili redovni ekonomski mehanizmi koji bi izmenili te relacije. Za kupca sa dinarskog području roba sa krunskog bila bi veoma jeftina (1/4 od cene na dinarskom području), što dobija čim zameni dinare za krune (i dobije ih četvorostruko) i kupi robu za krune. Na primer, ukoliko džak pšenice košta u Vukovaru 100 kruna, a u Beogradu 100 dinara, Beograđaninu se isplati da svojih sto dinara zameni za četristo kruna i kupi četiri džaka u Vukovaru umesto jednog u Beogradu. Ovo povećanje tražnje sa dinarskog na krunskom području dovelo bi do uravnoteženja, i to ili rastom cena pšenice na krunskom području (zbog povećane tražnje) ili jačanjem krune prema dinaru (zbog povećane tražnje kruna), a verovatno i jednog i drugog tako da bi kurs novca i odnos cena došli u sklad, kakvog, po Krajaču i Bićaniću, nije bilo.

\section{Kurs zamene krune i dinara}

Da kurs zamene krune i dinara treba da zavisi od njihovog odnosa kupovnih snaga, kako traže kritičari vlade, nije sporno. Pitanje je samo da li isključivo odnos kupovnih snaga treba da odredi kurs zamene. Mislim da ne, jer postoje i drugi činioci koje bi trebalo uzeti u obzir. Vidimo ih četiri.

Prvo, srpski dinar donosi novom dinaru vrednu metalnu podlogu koju kruna gotovo da nema (osim iz likvidacije AU banke). Srpska strana je tako u novac nove države uložila važan deo skromnog nacionalnog kapitala, iako bi za nju bilo bolje da je, umesto u sefove Narodne banke, uložen, na primer, u obnovu njenog bankarskog sistema, koji, zbog rata i okupacije, praktično nije postojao 1919, ili u druge produktivne poslove. Zbog nefundiranosti krune posle unifikacije pojavio se manjak podloge, ${ }^{23}$ što je značilo

${ }^{23}$ Doduše, u Zakonu o Narodnoj banci pomenuta je i državna imovina kao podloga, ali je to bilo više reklamno nego stvarno rešenje. Jer, podloga novca mora biti likvidna, znači ili metalna ili lako pretvoriva u metal da bi vršila svoju ulogu, što državne šume ili zgrade svakako nisu. 
kvarenje dinara, odnosno smanjenje poverenja koje se u njega može imati. Da nije došlo do spajanja s krunom, dinar bi zadržao jaku podlogu i omogućio zlatno važenje. Zbog slabe, razvodnjene podloge, novim zakonom o Narodnoj banci nije ni predviđena zamenljivost novčanica za metal, tako da je Kraljevina SHS zadugo ostala na papirnom važenju i čekala do 1931. da proglasi zlatni standard, a posle velikog francuskog zajma. Slabost papirnog važenja se ubrzo pokazala: tih godina emitovano je dosta dinara za potrebe pokrivanja državnog deficita, što je dovelo do smanjenja vrednosti dinara i što ne bi bilo moguće da je važio metalni standard. Zbog vredne podloge koju je dinar imao a kruna ne, prirodno je da vrednost dinara bude uvećana u odnosu na odnos kupovnih snaga.

Drugo, stanovništvo Srbije je tokom rata veoma oštećeno okupacionim kursom od dva dinara za jednu krunu, pa je unifikacija novca bila prilika da se dinarskom području ova šteta makar delimično nadoknadi kroz povoljniji odnos zamene. Takva pogodnost je u punoj meri sadržana $u$ pomenutom predlogu Saveza novčanih zavoda, a kroz sugestiju da se kurs zamene odredi na 2:1 umesto 1:1 baš zbog okupacione eksproprijacije.

Treće, kurs zamene nije smeo da bude previše povoljan kako ne bi privukao krune iz okolnih zemalja, kako je Ivo Belin govorio još krajem 1918. godine. Milijarde malo vrednih kruna čekalo je priliku da budu zamenjene za nešto vrednije, pa ih je trebalo odbiti od Jugoslavije, makar i uz pomoć kursa.

I četvrto, uticaj tržišnog kursa na kurs zamene bio je i neminovan i poželjan. Neminovan - stoga što je bio raspoloživ i poznat svima (novine su ga objavljivale), pa je predstavljao orijentir od koga kurs zamene nije smeo da previše odstupi da zamena ne bi izazvala velike proteste. Poželjan - jer je predstavljao svakodnevno vrednovanje dveju valuta od strane poslovnih ljudi, koji su najviše zainteresovani za njih i koji stoga poseduju najbolje informacije o svim činiocima, a polazeći od međunarodnih berzanskih vrednosti, unutrašnje trgovine i investicionih mogućnosti. U datim okolnostima, predstavljao je najobjektivniji element cele jednačine.

\section{Hacinova kritika}

Zanimljivu ekonomsku kritiku kursa zamene dao je slovenački ekonomista Janko Hacin. ${ }^{24}$ Načinio je misaoni eksperiment ustanovljavanja šta bi se dogodilo s kursom krune i dinara da predstavljaju valute u odvojenim zemljama. Pošao je od toga da su spoljni dugovi krunskog područja države relativno mali i izvoz priličan i zaključio da je platni bilans „verovatno aktivan“.

\footnotetext{
${ }^{24}$ Slovenski narod, 25. i 31. decembar 1919.
} 
S druge strane, spoljna zaduženost Srbije je vrlo visoka (oko 4 milijarde zlatnih franaka/dinara, sa, kako je procenjivao, godišnjom otplatom od 450 miliona tekućih dinara), a trgovinski bilans u 1919. veoma negativan, što je donosilo „izuzetno pasivan“ platni bilans. Iz tako različite situacije, a zbog potrebe da dinar depresira kako bi se popravio platni bilans, izvodio je neminovnost slabljenja kursa dinara prema kruni i zaključio da bi kurs bio bliže četiri dinara za jednu krunu nego vladinom predlogu za obrnuti odnos.

Hacinova logika je tačna u vrlo jednostavnom modelu bez kreditnih mehanizama, ali pada sa unošenjem realističnijih elemenata. Tako dinar ne mora da depresira ukoliko u model uključimo kreditne aranžmane i dozvolimo mogućnost da se tekući deficit finansira kroz novo zaduženje i da se stari dugovi ne isplaćuje u gotovom već refinansiraju novim zajmovima: tada uravnoteženja preko deviznog kursa nisu nužna. Drugim rečima, moguće je da bi kurs dinara bio znatno povoljniji prema kruni u realističnijem modelu valutnog kursa nego što tvrdi Hacin.

Drugo, Hacin je pretpostavio da će Srbija morati odmah da plaća sve obaveze po spoljnim dugovima, što se nije dogodilo. Pojednostavljeno rečeno, plaćanje predratnih zajmova Srbije zapelo je na pitanju da li da se otplata vrši u zlatnim ili papirnim francima, a plaćanje ratnih na pitanju njihovog tačnog iznosa. Jugoslavija je vrlo dugo vrdala i izbegavala plaćanja, uz delimične otpise od strane poverilaca. ${ }^{25}$

Treće, Hacin je izgubio iz vida jednu važnu stavku koja je menjala finansijsku sliku: ratne reparacije u korist Srbije (i Crne Gore). Nemačkoj je 1921. određeno da na ime reparacija plati 132 milijarde zlatnih maraka, od čega 50 milijardi tokom prvih decenija. Srbija je stekla pravo na $5 \%$ od toga, znači na 2,5 milijardi u prvom ciklusu i još 4 milijarde na vrlo dugi rok. Pored toga, Srbiji je određeno i 1,2 milijardi franaka reparacija od Austrije, Mađarske i Bugarske, pa je tako imala prava na iznos ratne odštete slične veličine njenim ukupnim spoljnim dugovima.

\section{Pitanje cena po zameni}

Ideja da će zamena novca dovesti do gubitka 3/4 novčane imovine bila je zasnovana na sledećem rezonovanju: zamena će smanjiti brojčani iznos novca u rukama posednika kruna (100 dinara umesto 400 kruna), ali cene najverovatnije neće biti brojčano smanjene već će u dinarima ostati iste kolike su bile u krunama (uglavnom zbog trgovačke pohlepe). Tako je Ivan Krajač tvrdio sledeće: „Predloženo vezanje obaju novčanica a u razmeru 4:1 na istom papiru, uzrokovat će četvorostruko skakanje cena u krunskom

\footnotetext{
${ }^{25}$ Videti: D. Gnjatović, Stari državni dugovi, Beograd 1991.
} 
području u novoj jedinici“, što će „najteže osetiti svi slojevi, a najviše sama država koja bi išla u susret katastrofi ako će morati plaćati činovništvu plaće $\mathrm{u}$ dinarima $\mathrm{u}$ istoj brojčanoj visini kako je... plaćala $\mathrm{u}$ krunama“. ${ }^{26} \mathrm{I}$ novine nisu zaostajale, pa je Slovenec pisao da bi zamena 4:1 imala „jedini efekat da bi cene strašno skočile tako da bi sve što danas košta 1 krunu koštalo 1 dinar. Da bi takva zamena donela potpun krah privrede ne može biti sumnje“". ${ }^{27}$

Ovde se očigledno radi o odsustvu elementarne ekonomske logike, što nije čudno kada se zna da su kao vodeći prečanski finansijski stručnjaci toga vremena figurirali pravnici zaposleni u bankama. Još je gore ukoliko su dobro razumeli stvar i svesno varali publiku. Prvo, kod zamene kruna za dinare po kursu 4:1 ne postoji mogućnost da cene ostanu brojčano iste, jer je opticaj sada samo jedna četvrtina prethodnog, pa je i obim kupovina samo jedna četvrtina prethodnog. Pošto na tržištu deluje konkurencija, trgovci moraju da snize cene na jednu četvrtinu da bi prodali robu, što mogu da učine bez negativnih posledica po sebe jer znaju da će i njihovi dobavljači smanjiti cene na jednu četvrtinu, pošto je novac sada četiri puta vredniji. Jednostavno, denominacija novca ili promena novčane jedinice ne utiču na realne vrednosti prihoda, dohotka ili imovine. Na kraju, iskustvo iz 1922. godine, kada je vršena zamena krunsko-dinarskih novčanica za dinarske pokazalo je da pomenutih problema sa cenama nije bilo. Drugo, zamena kruna je 1920. izvršena za krunsko-dinarsku novčanicu (kruna za krunu) pa nikakvih promena cena nije ni moglo ni trebalo da bude, a nije ni bilo, pa je Krajačeva tvrdnja besmislena.

\section{Devalvacija krune}

Među kritičarima zamene kruna po vladinom konceptu redovno je korišćen pojam „devalvacije krune“, odnosno „zakonska devalvacija“28 i stavljana primedba da država vodi „devalvacionu politiku“ na račun imalaca kruna i da je na kraju izvedena devalvacija krune. ${ }^{29}$ Zakonska devalvacija označava formalno smanjenje vrednosti krune, izraženo u zlatu, a zakonska vrednost austrougarske krune ustanovljena je 1892. godine i iznosila je 0,304878 grama zlata za jednu krunu, što potom nije menjano.

Primedba o grehu vlade zbog navodne zakonske devalvacije krune $u$ stvari znači da bi Jugoslavija trebalo da poštuje zakonsku obavezu obavezu AU banke i Austro-Ugarske po krunskim novčanicama u punoj zakonskoj

${ }^{26}$ Lj. Kosier, n. d., 275 i 291.

${ }^{27}$ Slovenec, 21. decembar 1919.

${ }^{28}$ Na primer, Lj. Kosier, n. d., 335.

${ }^{29}$ Devalvacija standardno označava smanjenje vrednosti novca, prvenstveno zvanične vrednosti u sistemu fiksnih deviznih kurseva. 
vrednosti, odnosno u zlatu i da, ranije ili kasnije, bude spremna da te novčanice isplati u zlatu po kursu iz 1892, a bez obzira na rat u međuvremenu i ogromno povećanje broja kruna u prometu.

Takav zahtev ne stoji ni pravno, ni moralno, ni ekonomski. Prvo, zamena nije donela formalnu devalvaciju krune pošto tom prilikom nije ni utvrđena njena nova zvanična vrednost izražena u zlatu (kao ni dinara), već samo odnos dveju valuta. Odlukom vlade o unifikaciji novca od 15. januara 1920. izričito je predviđeno da će se vrednost dinara (a time i krune) u zlatu odrediti kada se steknu uslovi, odnosno tokom prelaska na zlatni standard. Drugo, čak ni zvanična devalvacija ne bi padala na dušu vlade Kraljevine već isključivo AU banke, pošto bi samo predstavljala prilagođavanje već zaboravljene zvanične vrednosti u zlatu posleratnoj stvarnoj vrednosti krune. I treće, besmisleno je tražiti da Jugoslavija vrednuje postojeće krune po nedevalviranom, predratnom zlatnom paritetu i tako ih isplati imaocima, kao da u međuvremenu nije naštampano dvadeset puta više kruna i ona obezvređena. Ivo Politeo, kritičan i prema vladinom planu i prema maksimalističkim zahtevima protivnika, lepo je to izrazio: „Ne može se današnjoj kruni dati vrijednost predratne krune ili predratnog dinara kad je ona nema. Iz ničega se ne može stvoriti nešto". ${ }^{30}$ Jer, to bi značilo ogroman poklon posednicima malo vrednog papira i enormno opterećenje državne blagajne, ${ }^{31}$ što se ne može braniti ni na koji način osim zabavnom advokatskom vratolomijom da posednici imaju pravo da svoje krune zamene za zlato kod AU banke po kursu iz 1892, da je Kraljevina SHS pravni sledbenik Austro-Uugarske i da je stoga dužna da preuzme formalne obaveze po zlatnom kursu nestale monarhije i njene propale centralne banke. Ovo je ne samo besmisleno shvatanje pravnog kontinuiteta, već su ga Pariska mirovna konferencija i Senžermenski ugovor odbacili kroz jasnu odredbu iz člana 206 da krunske novčanice predstavljaju potraživanje isključivo prema AU banci u likvidaciji i nikom drugom. Naravno, nijednoj drugoj državi sa krunskog područja (ni Austriji i Mađarskoj) nije na pamet palo da prilikom zamene isplaćuje stare krune po zakonskom zlatnom kursu.

Kada bi se dovela do krajnjih konsekvenci, isplata kruna po zlatnom kursu značila bi prenošenje dela troškova finansiranja rata s poražene na pobedničku stranu! Naime, pošto su troškovi rata finansirani od strane Austro-Ugarske inflacionim krunama, to bi otkup obezvređenih novčanica po punoj predratnoj vrednosti od strane države Jugoslavije značio vraćanje

${ }^{30}$ I. Politeo, Narodna banka, Jugoslavenska njiva, 8. avgust 1919.

${ }^{31}$ Pošto je na teritoriji Monarhije pre rata u opticaju bilo 2,5 milijarde kruna, a na teritoriji Kraljevine SHS 1919. najmanje 5 milijardi, to bi značilo da nova država duguje domaćim posednicima kruna zlata za najmanje dva ukupna predratna opticaja kruna cele Monarhije u zlatu. 
krune na predratnu vrednost i poništavanje tog inflacionog obezvređenja, što bi donelo veliki transfer resursa iz budžeta na krunsko područje i naknadno (delimično) pokrivanje ratnih troškova Austro-Ugarske i njenih pokrajina od strane pobedničke Srbije. Stvar se još bolje vidi iz Srbije: radilo bi se o čistom transferu zlata u prečanske krajeve preko budžeta Jugoslavije, a bez ikakve koristi za Srbiju.

Priča o devalvaciji koristila se, očigledno, kao polemička tehnologija poslovnih krugova kojom se pokušalo sugerisati da Vlada namerno smanjuje vrednost novca u rukama posednika kruna, a to je ceo narod. Tako je Savez novčanih zavoda tvrdio da se radi o devalvaciji krune, i to „bezobzirnoj“ i „apsolutnoj“, ma šta to značilo, što „gotovo potpuno uništava znatan deo nacionalnog imetka vlastitih državljana". ${ }^{32}$ Ovakve hiperbole ukazuju da nema govora o ozbiljnoj analizi već o žučnom zastupanju sopstvenih interesa i njihovog predstavljanja kao opštih, a radi podbadanja javnosti. A interes je jasan: što bi kurs razmene bio viši za krunu to bi rezultat bio povoljniji po osnovni kapital i bilanse ovih novčanih zavoda. Lobiranje od strane poslovnih krugova postojalo je i pre jednog veka.

Takva propaganda imala je šanse na uspeh u narodu i stoga što je kod znatnog broja onih koji nisu razumeli šta se događa postojao fenomen koji je u ekonomskoj nauci poznat pod imenom iluzija novca. Radi se o takvom iracionalnom poimanju novca kod koga se njegova vrednost vezuje za nominalni iznos na samoj novčanici, a ne za njegovu stvarnu kupovnu moć (na primer, umanjenu inflacijom). Tako su mnogi podrazumevali da je kruna kruna, to jest da je ostala ista kakva je oduvek bila, a da joj vlada u Beogradu sada pobija vrednost. I oni su bili vrlo pogodni za manipulaciju, pa je zamena u hrvatskim krajevima zapamćena kao nepravedna.

\section{Objektivna krivica vlade}

Među kritičarima prisutan je i sledeći argument: posednici kruna nisu krivi za rast opticaja krune, već je to, posle ujedinjenja, domaća finansijska vlast. Stoga bi pravedno bilo da se uzme kurs valuta koji je preovlađivao prilikom ujedinjenja (krajem 1918) i da to bude stopa konverzije kruna u dinare. Takav stav zastupao je dr Avakumović decembra 1919, u polemici sa Nedeljkovićem. Avakumović je priznavao da se „namnoži(o) broj kruna toliko da im je svaka vrijednost pala“ i da je „uslijed tog velikog priliva nastalo takvo izobilje u krunama“. Predložio je za kurs zamene sledeće: „U tom pogledu odlučan bi bio moment sjedinjenja ovih pokrajina, kada je ministar finansija odredio relaciju 100:50. Pad vrijednosti kruna od to doba dalje

\footnotetext{
${ }^{32}$ Lj. Kosier, n. d., 244.
} 
nikako ne bi smio ići na štetu posednika kruna“. ${ }^{33}$ Slično tome, Bićanić je tvrdio: „Imaoci krunskih novčanica imali su moralno pravo, da od države traže kod izmjene kruna za dinare onaj tečaj koji je važio u momentu stvaranja države SHS“, takođe smatrajući da je tadašnjih 2:1 pravedno i da je jugoslovenska država kriva za kasniji znatan rast količine kruna. ${ }^{34}$ Taj stav ponavlja Boris Kršev kada kaže, takođe bez ikakve elaboracije: „Imaoci krunskih novčanica... imali su (makar) moralno pravo da zahtevaju od države da zamenu njihove valute za srpske dinare izvrše po kursu koji je važio u trenutku stvaranja države“". ${ }^{35}$

Ovaj moralni argument je pogrešan. Za opadanje vrednosti kruna prvenstveno je odgovorna AU banka, zbog stalne novčane emisije koja se prelivala u druge zemlje. Sva žigosanja, markiranja i administrativne mere $\mathrm{u}$ vreme posleratnih okolnosti nisu bile u stanju da zaustave prelivanje, pa ni Jugoslavija nije predstavljala izuzetak. Jedini pravi put predstavljala je zamena novčanica i unifikacija novca, što je tražilo dosta vremena. Ali, čak i da je ministarstvo odgovorno - to uopšte nije dovoljan razlog za davanje predložene beneficije posednicima kruna.

Avakumović i Bićanić propuštaju da primete da razvoj događaja nije samo oborio vrednost krune nego i povećao broj kruna u cirkulaciji, kako je navodio i sam Avakumović. Ukoliko, primera radi, pretpostavimo da je vrednost krune od 1. decembra 1918. do 1. januara 1920. prepolovljena, ali i da je cirkulacija kruna udvostručena (što su dve strane iste medalje), to bi značilo da posednici kruna drže u rukama manje vredan novac po jedinici, ali u većoj količini, što daje podjednaku realnu vrednost (izraženu stabilnim devizama, na primer). Stoga je pravedno zameniti krune po novom kursu jer se tako imaocima kruna obezbeđuje podjednaka vrednost $u$ dinarima kakva je bila u krunama (i u trenutku zamene i u trenutku osnivanja Kraljevine SHS).

Iz toga proizilazi da bi krajnje nepravedno bilo prihvatiti Avakumovićev predlog i izvršiti konverziju po starom paritetu, kao da broj kruna nije povećan. Takvim finansijskim potezom bi, u gornjem primeru, realna vrednost novčane imovine posednika kruna bila udvostručena.

Da je Vlada prihvatila radikalne zahteve i opredelila se za razmenu kruna za srpski dinar al pari ili 2:1 nema sumnje da bi zemlja bila preplavljena krunama, možda sa deset i više milijardi, što bi u prvi mah donelo veliki odliv realnog kapitala u inostranstvo u zamenu za bezvredne austrijske krune, a potom, kada država ne bude više u stanju da finansira veliko-

${ }^{33}$ Dr Avakumović, „Pred riješenjem valutnog pitanja“, Jugoslavenski (Hrvatski) Lloyd, 10. decembar 1919.

${ }^{34}$ R. Bićanić, $n$. d., 42.

${ }^{35}$ B. Kršev, Zamena novca postala politički problem, Danas, 22. juli 2008. 
dušnu zamenu, brzo štampanje dinara i visoku inflaciju. Bio bio to finansijski kolaps od koga bi i vlasnici kruna imali samo štete.

\section{Namerno zakašnjenje}

Varijacija istog zalaganja jeste Bićanićeva tvrdnja da je zamenu trebalo izvršiti odmah po stvaranju nove države, ali „da se ta zamjena nije namjerice izvršila na vrijeme... koncem 1918. ili početkom 1919. godine“. ${ }^{36}$ Teško je verovati da je Bićanić ovde ozbiljno mislio da je moguće za nekoliko nedelja po ujedinjenju izvesti zamenu novca koja je dobro pripremljena i stručno, i politički i tehnički.

U vreme boravka na Krfu srpska vlada nije ništa ozbiljno mogla pripremiti, jer se malo šta bitnog znalo: ni kada će rat biti završen, ni da li će i u kojim granicama zajednička država biti stvorena, ni kakva je monetarna situacija Austro-Ugarske i kakva će biti na dan kapitulacije, a o štampanju novčanica nije moglo biti reči. ${ }^{37}$

Ni po oslobođenju Beograda nije bilo moguće brzo izvesti zamenu. Ministar finansija stigao je u Beograd sredinom novembra i zatekao zgradu ministarstva potpuno ruiniranu, bez struje, dokumentacije i personala. ${ }^{38}$ Rat je tek bio na završetku, trebalo je finansirati vojsku, hraniti gladne na oslobođenoj teritoriji, stvoriti zajedničku državu, izboriti se za njene granice i priznanje, rešiti osnove državnog uređenja, izgraditi najnužniju državnu administraciju i drugo, što su svakako hitniji poslovi. Potom, trebalo je dogovoriti rešenje valutnog pitanja, od osnovne koncepcije, preko stope konverzije i svih tehničkih detalja do uloge Narodne banke. Ovo svakako nije samo stručno pitanje već i političko, pa je uključenje parlamenta, političkih stranaka i interesnih asocijacija iz raznih pokrajina bilo neminovno, a to u parlamentarnom poretku, na kakav je Srbija navikla pre rata, zahteva znatno više vremena nego što je nedelju-dve. Takođe, valutno pitanje ne bi bilo lakše dogovoreno oko nove 1919. nego kasnije, jer bi svi problemi iz 1919. i 1920. takođe pojavili, a neki u još zaoštrenijoj formi, i krajem 1918. godine. Zar ne bi kurs zamene postao vruće političko pitanje čim bi došao na dnevni red? Zatim, samo štampanje novih novčanica umnogome je određivalo dinamiku zamene, a ono, po svemu sudeći, nije moglo biti brže izvedeno. Na kraju, sklapanje mirovnih ugovora se oteglo, a od njihovih odredaba zavisila su pojedina rešenja zamene, na prvom mestu odgovornost AU banke, Austrije i Mađarske.

\footnotetext{
${ }^{36}$ R. Bićanić, $n$. d., 42.

${ }^{37}$ M. Ninčić, Naše valutno pitanje, 19-25.

${ }^{38}$ Ministarstvo finansija Kraljevine Jugoslavije 1918-1938, 21-22.
} 


\section{Zamena kruna u Srbiji}

Bićanić je tvrdio i da su „tokom 1919“ imaoci kruna u Srbiji zamenili svoje krune po kursu „u najmanju ruku“ od 2:1, što je daleko povoljnije nego 4:1 i što je išlo u korist Srbije, a na štetu Hrvatske. ${ }^{39}$ Njega i ovde sledi Kršev. ${ }^{40}$ Ova tvrdnja nije tačna.

Prvo, u Srbiji tokom 1919. nije bilo nikakve najavljene zamene koja bi se izvršila u određenom periodu po propisanom kursu, već je dinar stizao do stanovništva kroz državne plate, nabavke i druge isplate. Nije čudno što je država gledala da na području Srbije koristi srpski novac umesto okupacionog. Drugo, kurs krune i dinara tokom 1919. ni u jednom trenutku nije bio 2:1, kako tvrde Bićanić i Kršev: na grafikonu 1 se vidi da se berzanski kurs kretao od 2,7 sredinom februara do 4,5 u novembru. Državni kurs, koji je država koristila prilikom svojih transakcija, prikazali smo u tabeli 1. Kako se vidi, stanovništvo Srbije nije moglo da menja krune za dinare po kursu 2:1 tokom 1919. godine već samo po višem, pošto je 1 . januara 1919. državni već bio 2,5;1. Treće, prilikom markiranja kruna krajem 1919. pokazalo se da u Srbiji i dalje cirkuliše više stotina miliona kruna, što znači da nisu u celini zamenjene dinarima, kako tvrde Bićanić i Kršev.

$\mathrm{Na}$ kraju, ovaj način postepene zamene kruna za dinare mogli su koristiti i prečanski krajevi da su tokom 1919. upotrebljavali dinar u poslovnom saobraćaju, umesto što su se čvrsto držali krune. Deo prečana, u Vojvodini primao je dinare tokom 1919. godine i tako se pre formalne zamene oslobađao kruna koje su gubile vrednost.

\section{Zaključne napomene}

(1) Ne postoji način da se egzaktno proceni pravedan kurs zamene krune dinarom, kao što ni 1920. nije bilo moguće naći nedvosmislen kriterijum ili aritmetičku formulu kojom bi se on odredio. Samim tim nije moguće ni sada kao ni tada dati preciznu ocenu ove operacije, pa su i sve „tvrde“ ocene u ovom ili onom smeru nepouzdane, o čemu svedoči manjak argumenata i kod kritičara i kod nekih branilaca izvedene zamene.

(2) Potpisnik ovih redova veruje da operacija zamene, generalno gledano, nije loše izvedena i da je kritika najčešće neopravdana. Sam kurs zamene nalazi se u zoni prihvatljivih, realnih vrednosti, uzimajući u obzir kupovnu snagu obeju valuta, vrednost unete podloge, okupacioni kurs krune u Srbiji, potrebu odbijanja priliva kruna iz inostranstva i berzanski kurs u zemlji. Idealni kurs, verujem, može odstupiti od primenjenog za manje od

\footnotetext{
${ }^{39}$ E. Bićanić, $n$. d., 43.

${ }^{40}$ B. Kršev, Finansijska politika Jugoslavije 1918-1941, 112.
} 
jedne krune na dinar. Kritičari vlade koji su tvrdili da je kupovna snaga krune i dinara jednaka i zahtevali da kurs bude al pari ili 2:1 uopšte nisu bili u pravu, jer je dinar imao vidljivo veću kupovnu snagu i jer nije samo kupovna snaga relevantna za kurs zamene. Kako je tačno rekao Jože Šorn, oni koji su, i pored inflacione krune bez pokrića, tražili relaciju 1:1 „bili su ili naivni ili špekulanti“. ${ }^{41}$

U manjkavosti operacije mogu se ubrojiti izvesna sporost štampanja novčanica, koja je odložila zamenu, i činjenica da je odluku o zameni donela i sprovela vlada, bez parlamenta. Ali, nije izvesno da je u datim okolnostima moglo biti drugačije.

(3) Važan element delovanja vlade na unifikaciji valuta bila je razumna težnja da se izbegne veliki priliv malo vrednih kruna iz okolnih zemalja, koje bi onda bile zamenjene za solidni dinar i transferisane $u$ inostranstvo. Na taj način bi za Jugoslaviju bio izgubljen veliki realan kapital. Ta bojazan svakako je bila sasvim opravdana, a ne vidi se dobar alternativan način da se priliv spreči: zabrana uvoza kruna i izvoza dinara i deviza već se više puta pokazala neefikasnom.

(4) Vlasnici kruna u Jugoslaviji prošli su znatno bolje nego vlasnici u Austriji i Mađarskoj, zahvaljujući merama koje je država preduzela na zaštiti od poplave iz okruženja, a koje su usporile opadanje tržišnog kursa krune. Te mere svakako nisu bile savršene, što je razumljivo u datim okolnostima, ali su makar jednim delom „odvezale“ SHS krune od ostalih i donele relativni dobitak prema susedima. Ova razlika ne znači da su vlasnici kruna u Jugoslaviji odlično prošli, nego samo da ovdašnja država nije uništavala njihovu novčanu imovinu kao austrijska, već pokušavala da im ublaži gubitke.

(5) Po okončanoj unifikaciji vladala je dobra poslovna atmosfera i nisu se primećivale negativne posledice zamene po ekonomski život ni zemlje u celini, ni pojedinih krajeva. Nisu se ostvarila crna predviđanja o inflaciji ili deflaciji, kao što je ono ljubljanskog župana Ivana Tavčara da će po zameni „nastati neopisivo pomanjkanje novca“". ${ }^{42}$

(6) Poznavanje ekonomske nauke nije bilo rašireno na jugoslovenskom području, što se jasno vidi iz tadašnje literature. Kvalifikovani ekonomisti koji su se bavili novčanim pitanjima nisu bili brojni - Bajkić, Belin, Brezigar, Lunaček, Nedeljković, Radosavljević i Hacin - ali jesu znatno kompetentniji od manje ili više priučenih pravnika, kao što su Avakumović, Bićanić, Vrbanić, Andrej Gosar, Kosier, Krajač, Politeo, Dinko Puc, Tavčar i drugi. Među ekonomistima je posebno važnu ulogu odigrao Velimir Bajkić, kao pomoćnik ministra, lični prijatelj i desna ruka ministra Veljkovića.

\footnotetext{
${ }^{41}$ J. Šorn, Slovensko gospodarstvo v poprevratnih letih 1919-1924, 65.

${ }^{42}$ Slovenski narod, 17. decembar 1919.
} 
(7) Aktivnost mnogih učesnika u diskusija o unifikaciji novca nije bila motivisana težnjom da se dođe do istine ili da se učini nešto dobro za narod, već se često radilo o političkim i finansijskim interesima pojedinaca, grupa, partija, pokrajina, nacija i dr. Već prvi ozbiljniji ispit nova država je teško položila, što nije obećavalo svetlu budućnost.

Istorija se na kraju duhovito poigrala i dovela 19. februara 1920. u vladu, koja je neposredno realizovala zamenu kruna započetu samo tri dana ranije, Slovenačku narodnu stranku Antona Korošeca i Hrvatsku zajednicu Matka Laginje koje su prethodnih nedelja, zajedno sa svojim organima (Slovenec i Hrvat) i svojim intelektualcima (Gosar i Krajač), žestoko kritikovale tu istu zamenu. Potom je zamena nastavljena u mirnoj atmosferi.

Boško Mijatović

THE EXCHANGE OF AUSTRIAN CROWNS FOR DINARS IN 1920 (Part Two)

\section{Summary}

In the second part of this paper we discuss criticism regarding the policy of replacement of crowns with dinars, made by various authors. Their main claim was that the exchange rate of 4:1 was unfair toward owners of crowns, even plundering, because of allegedly equal purchasing power of the dinar and the crown at the time of replacement. However, no emprirical evidence was offered to support that statement. We present the evidence (mostly prices of several agricultural products) which shows that purchasing power of the dinar was significantly higher (probably 3-4 times). Another objection - that government intentionally missed to replace crowns immediately after the formation of the Kingdom of Serbs, Croats and Slovenes - is shown in this paper to be wrong because it was an impossible task for technical and political reasons. These authors even made some catastrophic predictions of economic collapse of the country due to the replacement of money, which never materialized. 